\title{
MINISTÉRIO PÚBLICO: TRANSFORMADOR DA REALIDADE SOCIAL OU REPRODUTOR DAS ESTRUTURAS DE PODER?
}

\author{
DEPARTMENT OF PUBLIC PROSECUTION: TRANSFORMING THE \\ SOCIAL REALITY OR REPRODUCING THE STRUCTURES OF POWER?
}

Alexandre José da Silva Mestre em Diversidade Cultural e Inclusão Social (Universidade Feevale/Brasil). Assistente de Promotoria de Justiça do Ministério Público do Rio Grande do Sul (Porto Alegre/Brasil).E-mail: alesaoleo@hotmail.com.

\section{Valdir Pedde}

Doutor em Antropologia Social (Universidade Federal do Rio Grande do Sul/Brasil). Professor na Universidade Feevale (Novo Hamburgo/Brasil).E-mail: valpe@feevale.br. 


\section{RESUMO}

O artigo centra sua análise sobre a atuação complexa e, às vezes, ambígua do Ministério Público no atual Sistema de Justiça Brasileiro. O texto busca, em um primeiro momento, definir o novo perfil da Instituição na Constituição Federal de 1988 e revisar as principais teorias críticas acerca da atuação dos seus Membros. Após, por meio de um esforço interdisciplinar e com o auxílio do método etnográfico, fazendo uso das técnicas de observação participante e entrevistas não-diretivas, os autores realizam um mergulho nas práticas institucionais dentro e fora de um processo judicial em busca de atendimento em saúde para uma criança. Desse mergulho emergem as tramas decorrentes das referidas práticas e seus desdobramentos, que indicam um movimento complexo e multifacetado invisível aos olhos desatentos e aos consensos naturalizados. Como resultado, temos evidenciada uma instituição transformadora da realidade social e, simultaneamente, reprodutora das tradicionais estruturas de poder: ora é emancipatória; ora, tutelar. Assim, o artigo constitui-se em um convite à reflexão a fim de que se possa perceber onde, como e quando o Ministério Público demonstra seus potenciais e, ao mesmo tempo, suas fragilidades.

Palavras-chave: Cidadania. Interdisciplinaridade. Ministério Público. Práticas jurídicas.

\section{ABSTRACT}

The article focuses its analysis on the complex and, sometimes, ambiguous operation of the Department of Public Prosecution in the present Brazilian Justice System. The text seeks, at first, to set the new profile of the Institution in the Federal Constitution of 1988 and to review the major critical theories about the performance of its Members. Then, through an interdisciplinary effort and with the help of the ethnographic method, making use of the techniques of participant observation and non-directive interviews, the authors dive into institutional practices, both in and out of a lawsuit demanding health care for a child. From this dive emerge the plots resulting from the practices and their consequences, indicating a complex and multifaceted movement which is invisible to inattentive eyes and naturalized consensus. As a result, evidence of an institution transforming social reality and, simultaneously, reproducing the traditional structures of power: sometimes emancipatory, others tutelary. Thus, the article is in an invitation to reflection in order to perceive where, how and when the Department of Public Prosecution demonstrates its potential and, at the same time, its weaknesses.

Keywords: Citizenship. Interdisciplinarity. Department of Public Prosecution. Legal practice. 


\section{INTRODUÇÃO}

Em uma obra de Boaventura de Sousa Santos (2003) ele pergunta: poderá o Direito ser emancipatório? Trata-se de uma pergunta muito apropriada para refletirmos sobre o papel e os desafios das instituições que compõem o Sistema de Justiça no Brasil. Naquela obra, Boaventura de Sousa Santos realiza um levantamento histórico do papel do Direito após a Revolução Francesa. Constata que no Estado Liberal emergente de então, havia uma relação dialética entre a regulação social e emancipação social mediada e assumida mais e mais pela regulação jurídica. Após 1848, com o triunfo do liberalismo, os embates pela emancipação social exprimiram-se na linguagem de contrato social e pela inclusão de maiores parcelas da população dentro deste contrato. Assim, esta relação entre regulação jurídica e emancipação social assumiu, especialmente na Europa, a forma de um Estado de Direito, o que possibilitou a ampliação da cidadania política (o sufrágio universal, entre outros) e social (entre outros, com o Estado Providência). De qualquer forma, este liberalismo político, tanto na sua faceta "demo-liberal" (que advogava a liberdade acima da igualdade), quanto socialdemocrata (que buscava a paridade entre liberdade e igualdade), tinha como seu contraponto a luta contra o conservadorismo, pois esse se apresentava inflexível à inserção de excluídos no contrato social. Contudo, com as crises do Estado de Bem-Estar Social e do Socialismo, emerge o Neoliberalismo, não como uma nova versão do liberalismo, mas como o renascimento do velho conservadorismo. Diante desse novo quadro histórico, a pergunta de Boaventura de Sousa Santos (poderá o Direito ser emancipatório?) emerge com força na atualidade e serve de pedra angular para uma oportuna reflexão sobre o papel de uma instituição grande, complexa e multifacetada que ocupa importantíssima função no Sistema de Justiça Brasileiro: o Ministério Público.

Sem a pretensão de apresentar uma resposta definitiva à instigante pergunta, mas a utilizando como ponto de partida e pano de fundo no debate, vamos, em um viés menos jurídico e mais interdisciplinar, contribuir com referenciais teóricos e empíricos capazes de revelar uma atuação institucional, às vezes, transformadora da realidade social (emancipação) e, às vezes, reprodutora das desigualdades sociais (dependência). Ora, no aspecto formal, não resta dúvida de que o Ministério Público possui a missão de defender a nova ordem político-jurídica de 1988, de ser agente de transformação social, de exercer o papel de fomentador da cidadania e de indutor e fiscalizador de políticas públicas, especialmente em uma sociedade marcada pelo igualitarismo jurídico e pela desigualdade social. Nesse sentido, conforme veremos na revisão da literatura, seus membros - Promotores de Justiça e Procuradores de Justiça - são "promotores de fato" (SILVA, 2001a) e possuem práticas "mediadoras" (ROS, 2009), "pró-ativas" (LOUREIRO, 2010) e "resolutistas" (GOULART, 2013). Todavia, com um olhar antropológico e uma aproximação etnográfica, o que poderia revelar uma investigação mais "de perto e de dentro" (MAGNANI, 2002)? 
Assim, vamos propor - para além da legislação institucional, dos discursos oficiais e dos organogramas de gestão, um "mergulho em profundidade", utilizando a feliz expressão de Velho (1978, p. 37), nas práticas do Ministério Público a partir das trajetórias, narrativas e subjetividades de um pai que necessitou judicializar o direito à saúde de sua filha, criança que sofreu uma lesão medular em acidente doméstico e ficou internada em um hospital em estado vegetativo dependente de um respirador externo e à espera de uma estrutura de atendimento home care ${ }^{1}$ para sobreviver.

Na primeira parte deste artigo, com base em uma breve revisão da literatura, apresentaremos os principais traços do novo perfil do Ministério Público e alguns trabalhos que tensionam os modelos de atuação de seus membros. Em seguida, a partir dos dados coletados no campo de pesquisa, descreveremos, de forma resumida, o caso referido no parágrafo anterior, destacando os dramas, as peregrinações e as desconfianças do genitor em busca de direitos em uma Promotoria de Justiça da Infância e da Juventude. Nessa etapa, foi utilizado o método etnográfico, em especial as técnicas da observação participante, entrevista não-diretiva, conversas informais e análise de documentos. Por fim, arriscaremos - a partir desse cotidiano vivido em busca de direitos - algumas reflexões sobre as práticas da Instituição e seus desdobramentos em termos de cidadania. Tais reflexões, tangencialmente, poderão servir de substrato para a formulação de respostas a pergunta tão desafiadora à moda de Boaventura de Souza Santos. O artigo é, sobretudo, um convite ao debate em uma perspectiva crítica e interdisciplinar.

\section{O NOVO PERFIL POLÍTICO-JURÍDICO DO MINISTÉRIO PÚBLICO NA CONSTITUIÇÃO FEDERAL DE 1988}

A Constituição Federal de 1988 inaugurou um novo paradigma para o Ministério Público. Ela erigiu a instituição à condição de permanente e essencial à função jurisdicional do Estado, cuja missão é a defesa da ordem jurídica, do regime democrático dos interesses sociais e individuais indisponíveis (art. 127, caput, da CF88). Nesse sentido, o órgão transitou da defesa do governante (pré-1988) à defesa da sociedade (pós-1988). De fato, a Constituição Cidadã foi a "certidão de (re)nascimento" (ARANTES, 1999, p. 87) do Ministério Público. A moldura da instituição ganhou novos contornos e, consequentemente, desafios.

A posição topológica do Ministério Público, que foi estrategicamente incluído no capítulo atinente às Funções Essenciais à Justiça (Capítulo IV, artigo 127 a 130-A), também gera curiosidade, pois a Instituição não possui

\footnotetext{
${ }^{1}$ Home Care ou Assistência Domiciliar é uma modalidade de prestação de serviços na área da saúde que visa à continuidade do tratamento hospitalar no domicílio.
} 
vinculação funcional a qualquer dos poderes do Estado. Sobre as profundas e notáveis mudanças de perfil do Ministério Público, vale destacar a precisa lição de Mazzilli (2008, p. 4):

Hoje, é uma instituição e não um órgão de governo; destina-se à defesa da sociedade, e não á defesa do governante; tem autonomias, goza de independência funcional e não sofre subordinação hierárquica; está voltado à defesa do regime democrático e não à mera representação processual das pessoas jurídicas de Direito Público interno; exerce parcela direta da soberania do Estado, quando condiciona o exercício da ação penal pública.

Hoje o Ministério Público abrange o Ministério Público da União, que compreende o Ministério Público Federal, Ministério Público do Trabalho, Ministério Público Militar, Ministério Público do Distrito Federal e Territórios, e o Ministério Público dos Estados. Atualmente, a Instituição é independente e autônoma, tendo orçamento, carreira e administração próprios. Isso tudo para garantir que o Órgão desempenhe com total independência suas nobres atribuições de fiscal da lei e defensor do povo, mesmo contra o próprio Estado. Tanto que os membros do Parquet possuem como garantias a vitalicidade ${ }^{2}$, a inamovibilidade ${ }^{3}$ e a irredutibilidade ${ }^{4}$ de vencimentos para que exerçam as atividades e alcancem as finalidades da instituição com zelo e sem pressões externas.

Assim, o Ministério Público possui, a partir do artigo 129 da CF, uma diversificada atuação seja na esfera penal ou cível. Na penal, o Parquet é o titular privativo da ação penal pública, ou seja, o responsável pela persecução penal. Também é o responsável pelo controle externo da atividade policial e possui o poder de requisitar diligências investigatórias e inquéritos policiais. No campo cível, especialmente a partir de 1988, a Instituição passou a atuar com maior intensidade na proteção dos direitos das crianças e adolescentes, dos idosos e pessoas com deficiência, do patrimônio público e probidade administrativa, do meio ambiente e consumidor, o que lhe conferiu gradativamente legitimação e visibilidade social.

\footnotetext{
${ }^{2}$ A garantia da vitalicidade é uma condição especial de permanência e definitividade no cargo. O membro é vitaliciado após dois anos de exercício, o que significa que, desde então, não pode mais perder o cargo, salvo por sentença judicial transitada em julgado (irrecorrível).

${ }^{3} \mathrm{~A}$ inamovibilidade é a garantia de que, uma vez titular do respectivo cargo, o membro do Ministério Público somente poderá ser removido ou promovido por sua própria iniciativa, salvo uma única hipótese. Trata-se da hipótese da remoção por motivo de interesse público, mediante decisão do órgão colegiado competente do Ministério Público, por voto da maioria absoluta de seus membros, assegurada a ampla defesa. Tal garantia visa à proteção do membro para o pleno e livre exercício das suas funções institucionais.

${ }^{4}$ A garantia da irredutibilidade significa que seus membros não podem ter seus subsídios reduzidos.
} 
O Ministério Público possui, para cumprir sua missão e por expressa previsão legal, legitimidade para propor ações civis públicas, instaurar inquéritos civis, firmar termos de ajustamento de conduta, expedir recomendações aos órgãos públicos e realizar audiências públicas com a sociedade. Esses últimos mecanismos são de grande importância, pois permitem, na esfera extrajudicial, um diálogo com e entre o poder público e a sociedade civil. Aliás, a utilização de tais instrumentos, segundo Sadek (2009b, p. 35), é "uma forma de fazer justiça que fortalece a instituição; que garante direitos; que proporciona diálogos; que facilita a convivência futura”. Não por outro motivo, tais mecanismos deveriam ser utilizados prioritariamente em detrimento da mera judicialização.

Por tudo isso, não cabe mais a lembrança do órgão meramente acusador (promotor do júri) ou interveniente (promotor fiscal da lei), mas o papel de agente ativo, detentor de parcela do poder político, transformador da sociedade, incumbido de zelar não apenas pelo cumprimento das garantias fundamentais, mas também exigindo do próprio Estado o implemento de políticas públicas que as assegurem. Nesse sentido deve ser um agente da vontade política transformadora (GOULART, 2006, p. 137):

De acordo com a vontade popular explicitada na Constituição da República, o Ministério Público deve constituir-se em um dos mais importantes agentes da vontade política transformadora, cabendo-lhe a tarefa de definir e participar de ações político-jurídicas modificadoras da realidade, objetivando a construção do projeto constitucional de democracia (a sociedade livre, justa e solidária, na qual o desenvolvimento sócio-econômico-cultural deve estar voltado para a erradicação da pobreza e da marginalização, para a redução das desigualdades sociais e regionais e para a promoção do bem de todos).

À guisa de conclusão deste tópico, é possível afirmar que existem dois Ministérios Públicos bastante distintos: um antes e outro depois de 1988. No período anterior, o Parquet "exercia a dupla e dúbia função de representar judicialmente tanto o Estado quanto o interesse público" (ROS, 2009, p. 32). Já depois da Constituição Federal de 1988, que representou a certidão de (re)nascimento da Instituição, conquistou uma "independência bidimensional: externa e interna" (ARANTES, 2007, p. 329). Hoje o novo Ministério Público possui a missão de defender a ordem jurídica, os valores democráticos e os direitos sociais. Tem, sobretudo, a tarefa de ser agente de transformação e não de reprodução das desigualdades sociais. Essa é a vocação atual do Ministério Público. É a sua potencialidade. Nessa esteira, é "um ator político relevante, um ator político de primeiríssima grandeza" (SADEK, 2009b, p. 31). 
Todavia, a atuação do Ministério Público não está livre de análises e de reflexões, uma vez que as práticas dos seus membros e servidores devem corresponder à grandeza de sua missão constitucional, sob pena da vontade do poder constituinte e da letra da norma constitucional ser apenas mais uma mentira que a sociedade usa para sobreviver e reproduzir seus privilégios, ou seja, ser apenas mais uma página repetida na já conhecida história cultural e política de distanciamento entre o formal e o real no Brasil. Uma disjunção que deveria encontrar limites exatamente nos órgãos responsáveis pela aplicação, fiscalização ou interpretação da lei.

\section{IDENTIFICANDO PADRÕES E CLASSIFICANDO FORMAS DE ATUAÇÃO DO MINISTÉRIO PÚBLICO: UMA BREVE REVISÃO DA LITERATURA}

O Ministério Público deve ser analisado por meio de suas práticas nos processos judiciais, nos expedientes administrativos e na relação com a sociedade e não apenas em seu aspecto formal. A sua práxis é que vai explicitar um Ministério Público vivo e complexo. Portanto, nesse subitem, a revisão da literatura precisou se aproximar de obras e autores que realizam a análise da Instituição, não apenas com base na simples letra da lei, mas com assento nas práticas do Órgão. Tal estudo envolveu a definição de conceitos e de tipos ideais que servirão - mais à frente - para a análise das práticas vividas e percebidas durante o trabalho de campo dentro de uma Promotoria de Justiça.

\subsection{MINISTÉRIO PÚBLICO DEMANDISTA E MINISTÉRIO PÚBLICO RESOLUTISTA}

O conceito de Ministério Público demandista e resolutivo, construído por Goulart (2013), ajuda a diferenciar as práticas do antigo (pré-1988) e o novo (pós-1988) Ministério Público. O conceito distingue o primeiro como aquele que tem seu horizonte voltado às demandas no Poder Judiciário e o segundo que, ao se politizar e desjurisdicionalizar, tem seu norte voltado à solução direta das questões referentes aos interesses sociais, coletivos e difusos. Nessa esteira, Goulart faz uma profunda reflexão sobre a crise entre o antigo (demandista) e o novo (resolutivo) perfil do Ministério Público. Afirma que a instituição vive uma fase de transição e, logo, uma crise de paradigma, razão pela qual conhecer tal classificação e refletir sobre ela é fundamental para efetivar as mudanças culturais e estruturais necessárias à Instituição.

O autor entende a crise como a situação em que "o velho morreu e o novo ainda não conseguiu afirmarse” (GOULART, 2006, p. 137). A superação dessa crise não exige, necessariamente, reformas legislativas, mas uma "interpretação recontextualizadora das normas constitucionais e legais que definem sua estrutura, seus objetivos e atribuições" (GOULART, 2013, p. 201). Conforme o autor, o modelo demandista restringe-se ao processo judicial, e, por conseguinte, limita sua atuação a casos individuais, quando de fato deveria preocuparse mais com os interesses coletivos e difusos. Entretanto, no modelo resolutista (GOULART, 2013, p. 202) 
[...], o Ministério Público leva às últimas consequências o princípio da autonomia funcional, priorizando a solução direta das questões que the são postas pela sociedade. Com essa perspectiva, o inquérito civil transforma-se em instrumento de resolução de casos, objetivando, de forma imediata, o ajustamento de conduta e outras formas de composição que atendam ao interesse social. Deve partir para o ajuizamento de ação civil pública apenas quando esgotadas todas as possibilidades de solução negociada. A disputa judicial, nesse novo modelo, deve ser encarada como objetivo mediato do Ministério Público na esfera cível, mormente na tutela dos interesses transindividuais.

O Ministério Público, diante do seu novo contorno constitucional, deve se afastar do demandista e se aproximar do resolutista. Mas isso não é tão simples e óbvio. Aqui também tem uma distância entre o Brasil formal e o Brasil real. A questão parece ser identificar - seja na função da persecução penal ou da concretização dos direitos sociais - qual dos "Ministérios Públicos" está em ação nos fóruns e nas promotorias lotadas de processos e de pessoas em busca de direitos. O demandista ou o resolutista?

Assim, na perspectiva do autor, o antigo Ministério Público (demandista) ainda convive com o novo Ministério Público (resolutista), o que instaura uma crise e dificulta a consolidação da instituição como agente da vontade política transformadora. O MP resolutista implica o uso de instrumentos legais adequados, a participação na vida social e a ocupação de espaços políticos. Ao contrário do demandista, o MP resolutivo tem mais capacidade para entender o sucesso ou o fracasso de uma política pública. Atualmente a grande questão é saber - se a Instituição e seus membros - estão mesmos dispostos a ocuparem novos espaços políticos, dialogarem com outros atores sociais e, sobretudo, intervirem no processo de formulação de políticas públicas. Eis aí o ponto crucial - o ponto que distingue um MP demandista e um MP resolutivo.

A teoria formulada por Goulart tem implicação direta com a cidadania dos sujeitos atendidos nas Promotorias de Justiça, pois o Ministério Público demandista, com suas práticas conservadoras, apenas judicializa os problemas sociais e simplesmente tutela o cidadão. Ele tende por substituir o cidadão na arena política judicializando caso a caso as demandas que no fundo são coletivas, como, por exemplo, a falta de determinado medicamento nas farmácias públicas ou de médicos nos postos de saúde. Nesse sentido, o Parquet não visualiza o problema de um cidadão como uma possível demanda coletiva e resolve o caso de quem chega lá, o que acaba por reforçar a centralidade do Estado e não propiciar uma emancipação cidadã. Por outro lado, o Ministério Público resolutivo é o novo caminho que a Instituição poderia seguir para consolidar seu papel na luta pela democratização das relações sociais e pela universalização dos direitos da cidadania. Nesse ponto, vale citar novamente Goulart (2013, p. 202-203): 
O Ministério Público resolutivo é ativo no trabalho de construção da sociedade livre, justa e solidária [...]. Na esfera cível, assume o papel de agente político que the foi confiado pela sociedade, superando a perspectiva meramente processual de suas intervenções. Ao politizar sua atuação, ocupa novos espaços, habilita-se como negociador e indutor de políticas públicas, age integralmente e em rede com os demais sujeitos coletivos nos mais diversos níveis - local, regional intraestatal, estatal, regional supraestatal e global. O Judiciário torna-se espaço excepcional da sua atuação. Esse é o novo caminho que o Ministério Público deve seguir para consolidar o seu papel de agente privilegiado da luta pela democratização das relações sociais e pela globalização dos direitos da cidadania.

\subsection{PROMOTORES DE GABINETE E PROMOTORES DE FATO}

A cientista política Silva (2001b, p. 134-135), com base especialmente em suas entrevistas, discute as formas de atuação de um grupo de Promotores de Justiça de São Paulo e distinguia os "promotores de fato" e os "promotores de gabinete":

Definirei o promotor de gabinete como aquele que, embora utilize procedimentos extrajudiciais no exercício de suas funções, dá tanta ou mais relevância à proposição de medidas judiciais e ao exame e parecer dos processos judiciais dos quais está encarregado. Mais importante, o promotor de gabinete não usa os procedimentos extrajudiciais como meios de negociação, articulação e mobilização de organismos governamentais e não-governamentais. Já o promotor de fato, conquanto proponha medidas judiciais e realize atividades burocráticas ligadas às suas áreas, dá tanta ou mais importância ao uso de procedimentos extrajudiciais, mobilizando recursos da comunidade, acionando organismos governamentais e não-governamentais e agindo como articulador político.

$[\ldots]$

O promotor de gabinete não se vê, pois, como autoridade que deve cobrar continuamente do poder público a implementação de políticas e programas sociais. o promotor de fato, por sua vez, estabelece contatos, define prioridades, toma iniciativas, articula forças locais e participa de campanhas, mobilizações e eventos. [...]. As ações civis públicas são propostas quando os procedimentos extrajudiciais não surtiram efeito ou quando não há possibilidade de contato ou negociação, como nos casos de violação de direitos por órgãos estaduais e federais.

Em outra obra, a autora apresenta resultado importantíssimo da sua pesquisa no que concerne à imagem que os Promotores de Justiça pesquisados possuem sobre o Ministério Público e a sociedade (SILVA, 2001a, p. 19): 
Uma outra auto-imagem diz respeito ao lugar mesmo do MP, na representação dos promotores observados. Por um lado, revelam uma instituição visceralmente vinculada à sociedade; por outro, reconhecem-na como órgão do Estado. Sob essa perspectiva, subjaz outra imagem: atuam no interior de uma sociedade frágil, desarticulada, debilmente provida de instituições capazes de formalizar e endereçar suas demandas às agências públicas e políticas capazes de processá-las. Daí a importância de um órgão forte, politicamente neutro, porém comprometido com as lutas e as reivindicações sociais. Daí o papel saneador do MP. Ora, o curioso é que justamente o que se reivindica como princípio de agir democrático é algo que também pode ser identificado nas origens do pensamento autoritário brasileiro.

A visão dos próprios Promotores de Justiça de que atuam no interior de uma sociedade frágil, que não é capaz de se organizar e reivindicar seus interesses e direitos, é muito representativa para compreender porque determinadas práticas são absolutamente tutelares e, consequentemente, acabam por fortalecer a centralidade do Estado. Aqui é possível, entre outras possibilidades interpretativas, vislumbrar o reflexo de um passado escravocrata, autoritário e patrimonialista, especialmente quando um grupo arvora-se na condição de substituto da sociedade para representar os interesses desta mesma sociedade, o que "em última análise remete a modelos de cooptação política nos moldes daqueles apresentados em trabalhos clássicos da sociologia política brasileira" (ROS, 2009, p. 38-39).

\subsection{MINISTÉRIO PÚBLICO TUTELAR, REVOLUCIONÁRIO E MEDIADOR}

Ros (2009) sugeriu três tipos distintos de atuação da Instituição na interação com os segmentos da sociedade civil: a) o tutelar que busca substituir a sociedade civil; b) a revolução processual que se coloca como novo locus de representação política; e c) o mediador que busca ser um órgão de mediação entre vários setores da sociedade civil e do Estado, sendo capaz, por sua posição estratégica na arquitetura institucional, de promover coordenação entre vários grupos de interesses e movimentos sociais sem se tornar, contudo, insensível a eles.

No primeiro tipo de atuação, o Ministério Público age como um órgão tutelar, que busca, ao representar a sociedade civil, substituí-la, o que gera uma série de implicações de caráter verticalizado e paternalista. Nesse sentido, vale citar o longo trecho do artigo de Ros (2009, p. 38-39):

A leitura realizada pelos autores que podem ser enquadrados nesta perspectiva vê o Ministério Público fundamentalmente como um órgão tutelar, que busca, ao representar a sociedade civil, substituí-la, [...]. Os influentes estudos de Rogério Bastos Arantes (1999; 2002), bem como os de Fábio Kerche (2007) e Júlio Aurélio 
Vianna Lopes (1998; 2003) são exemplos dessa visão que, em última análise remete a modelos de cooptação política no moldes daqueles apresentados em trabalhos clássicos de sociologia política brasileira, como os de Simon Schwartzman (1982) e Raymundo Faoro ([1958] 2001). De acordo com essa visão, o voluntarismo político do órgão, a orientação ideológica de seus membros e a busca do papel politizado da instituição seriam informados por uma visão da sociedade civil brasileira essencialmente incapaz de defender seus próprios interesses, o que seria duramente agravado por instituições políticas (Executivo e Legislativo, especialmente) insatisfatórias no cumprimento de seu papel representativo. Trata-se, portanto, de um enfoque que ressalta o caráter verticalizado e mesmo paternalista da atuação do órgão, que em certos momentos assemelha-se a visões como o autoritarismo instrumental de que fala Wanderley Guilherme dos Santos (1978). Esse enfoque, portanto, vê com maus olhos o protagonismo do Ministério Público na defesa dos interesses públicos e difusos não apenas porque manteria amesquinhada a sociedade civil, tornando-a permanentemente dependente do órgão, mas também porque este modo de atuação ameaçaria inclusive a própria independência funcional da instituição. Desta ação de tutela do Ministério Público em relação à sociedade civil resultaria um duplo movimento perverso, dificultando, por um lado, no momento presente, iniciativas emancipadoras por parte da sociedade civil e, por outro lado, em médio e longo prazo, comprometendo a autonomia da instituição ante sua politização, considerada excessiva.

Já a atuação classificada como revolução processual apresenta, ao contrário da anterior, uma visão otimista do Ministério Público. Ela ressalta que é da interação entre Ministério Público e a sociedade civil que emergem possibilidades de transformação da realidade social. Uma vez o Ministério Público ligado aos movimentos sociais da sociedade civil, tende a gerar uma "função de proteção de minorias e de diversos grupos formadores da sociedade civil" (ROS, 2009, p. 40), anunciando a existência de um poder, pelo menos virtualmente transformador da realidade social e fomentador do diálogo.

No terceiro tipo de atuação, o Ministério Público apresenta-se como um órgão de mediação, nem tutelar e nem revolucionário. Essa visão destaca tanto as potencialidades como as limitações da atuação do Órgão. Logo, trata-se de uma visão intermediária que alerta para os equívocos das anteriores leituras e para os cuidados metodológicos que se devem ter quando se analisa uma instituição grande, complexa e multifacetada (ROS, 2009, p. 42-43):

No caso, se o Ministério Público não pode ser enquadrado como pretenso substituto da sociedade civil, também não pode ser colocado como agente promotor de transformações sociais significativas. Ao invés disso, os autores advogam ser 
- Ministério Publico brasileiro uma espécie de órgão de mediação entre vários setores da sociedade civil e do Estado, sendo capaz, por sua posição estratégica na arquitetura institucional, de promover coordenação entre vários grupos de interesses e movimentos sociais sem se tornar, contudo, insensível a eles.

As classificações propostas por Ros, com base em sua revisão da literatura, ajudam a identificar e analisar as práticas encontradas durante a coleta de dados. Elas são fundamentais para apontar no recorte proposto nesta pesquisa que tipo de Ministério Público ocupa a Promotoria de Justiça onde será realizada a pesquisa: o tutelar, o revolucionário ou o mediador. Por fim, Ros encerra o seu artigo evidenciando a necessidade de estudos mais específicos e menos generalistas a respeito dos novos papéis assumidos pelo Ministério Público a partir da década de 1980. Nesse sentido, embora evidente a carência de pesquisas nesta área, as ciências sociais começam a olhar com maior interesse para o Ministério Público e suas práticas.

\subsection{MINISTÉRIO PÚBLICO REATIVO E MINISTÉRIO PÚBLICO PRÓ-ATIVO}

O artigo de Loureiro (2010) trabalha com o conceito de Ministério Público reativo e pró-ativo para concretização dos Direitos Fundamentais. Ele afirma que o modelo reativo de atuação pressupõe que o Ministério Público deva ser provocado, direta ou indiretamente, para atuar na defesa da ordem jurídica, do regime democrático e dos direitos sociais e individuais indisponíveis. Por outro lado, a atuação pró-ativa do Ministério Público deve ser mais aproximada à ideia de proteção preventiva e não à dimensão repressiva natural de seu trabalho.

As categorias utilizadas no artigo serão importantes para a presente pesquisa porque transcendem uma determinada área de atuação e identificam posturas atreladas ao antigo e ao novo Ministério Público. Loureiro advoga que a postura pró-ativa encontra respaldo na nova ordem constitucional e, por meio dela, é possível reduzir a violação de direitos fundamentais e obter a efetividade de direitos sociais com políticas públicas efetivas, sem aumentar o número de membros do Ministério Público, promovendo-se fortes parcerias com as comunidades, bem como se utilizando de abordagens de combate a fatores de risco, como a ausência de transparência dos gastos públicos, a escassa participação da sociedade no planejamento e na execução de políticas e de orçamentos públicos, o clientelismo político, o tráfico de influência, o assistencialismo, o paternalismo, a dificuldade de acesso às informações e de acesso ao Judiciário. Por oportuno, vale citar a hipótese levantada por Loureiro (2010, p. 11):

Ainda restam realizar estudos, mas a hipótese é que a maior parte dos esforços do MP seja de natureza reativa, embora se tenha demonstrado interesse numa postura pró-ativa, através de atitudes isoladas ou conjuntas de promotores e procuradores ou 
na definição de políticas institucionais afirmativas na promoção e defesa de direitos fundamentais. É que, de fato, existe uma demanda tão grande de atividades ligadas ao Poder Judiciário e às relacionadas às notícias de violação de direitos fundamentais, que as atividades pró-ativas, ligadas à proteção preventiva, ficam mais em segundo plano. Reorientar as atividades do MP para privilegiar uma proteção preventiva poderia importar um impacto tão grande na organização que poderia desnortear o trabalho que já é desenvolvido. Portanto, sua introdução poderia ser realizada através de reformas pontuais na organização, sob premissas claras.

Portanto, além das categorias propostas pelo autor, é possível perceber, mais uma vez, a premente necessidade de novos estudos e outros olhares sobre a atuação do Ministério Público.

\subsection{QUAIS AS SEMELHANÇAS ENTRE OS MODELOS DE ATUAÇÃO ENCONTRADOS NA REVISÃO DA LITERATURA?}

Para melhor compreensão e visualização do ponto, foi criado um quadro com as principais características de cada modelo de atuação formulado pelos autores citados na revisão de literatura. Tal esquema tem o objetivo de sistematizar a ideia central e os conceitos de cada um dos autores e, com isso, facilitar algumas análises e reflexões futuras.

Quadro 1 - Modelos de atuação fornecidos pela literatura

(continua)

\begin{tabular}{|l|l|l|}
\hline Autor & $\begin{array}{l}\text { Modelo de } \\
\text { Atuação }\end{array}$ & Características \\
\hline Goulart & Demandista & $\begin{array}{l}\text { - ação judicial como objetivo imediato do MP; } \\
\text { - horizonte voltado às demandas no Poder Judiciário; } \\
\text { - transfere ao Poder Judiciário demandas de caráter coletivo e social; } \\
\text { - inquérito civil é reduzido a simples instrumento de coleta de provas para ajuizar ações; }\end{array}$ \\
\hline Goulart & Resolutista & $\begin{array}{l}\text { - ação judicial como objetivo mediato do MP; } \\
\text { horizonte voltado à solução extrajudicial das questões postas pela sociedade; } \\
\text { - inquérito civil é para resolver diretamente os casos e facilitar ajustes que atendam aos } \\
\text { interesses sociais; }\end{array}$ \\
\hline ação judicial só após esgotadas todas as possibilidades de negociação e diálogo; \\
ocupa novos espaços, habilitando-se como negociador e indutor de políticas públicos;
\end{tabular}


(continuação)

\begin{tabular}{|c|c|c|}
\hline Autor & $\begin{array}{l}\text { Modelo de } \\
\text { Atuação }\end{array}$ & Características \\
\hline \multirow[t]{2}{*}{ Silva } & $\begin{array}{l}\text { Promotor de } \\
\text { Gabinete }\end{array}$ & $\begin{array}{l}\text { - } \text { aquele que, embora utilize procedimento extrajudicial, dá tanta ou mais relevância à propo- } \\
\text { situra de medidas judiciais; } \\
\text { - não utiliza os procedimentos extrajudiciais como meios de negociação, articulação e mobili- } \\
\text { zação de organismos governamentais e não-governamentais; } \\
\text { - não cobra continuamente do poder público a implementação de políticas e programas } \\
\text { - sociais; } \\
\text { - } \text { as demandas são postas ao Promotor; }\end{array}$ \\
\hline & $\begin{array}{l}\text { Promotor de } \\
\text { Fato }\end{array}$ & $\begin{array}{l}\text { - } \text { aquele que dá tanto ou mais importância para o uso de procedimentos extrajudiciais, mo- } \\
\text { bilizando recursos da comunidade, acionando organismos governamentais e não-governa- } \\
\text { - } \text { realiza atendimento ao público, reuniões, palestras e orientações e ainda participa de cam- } \\
\text { - } \text { panhas, projetos e até ajuda a fundar organizações não governamentais; } \\
\text { - } \text { elege as demandas prioritárias para atuar; } \\
\text { - imagem mais favorável quanto ao grau de organização da sociedade; } \\
\text { - } \text { as novas funções constitucionais são usadas para transformação da sociedade; }\end{array}$ \\
\hline \multirow[t]{2}{*}{ Loureiro } & Reativa & $\begin{array}{l}\text { - } \text { - ideia de proteção repressiva; } \\
\text { - demanda grande de atividades ligadas ao Poder Judiciário, relevando a segundo plano uma } \\
\text { atuação preventiva; }\end{array}$ \\
\hline & Pro-Ativa & $\begin{array}{l}\text { - } \text { pressupõe que o MP deve atuar de ofício; } \\
\text { - ideia de proteção preventiva; } \\
\text { - atividades mais ligadas às parcerias com a comunidade e ao combate a fatores de risco (a } \\
\text { planejamento e na execução de políticas e de orçamentos públicos, o clientelismo político, o } \\
\text { tráfico de influência, o assistencialismo, o paternalismo, a dificuldade de acesso às informa- } \\
\text { ções e de acesso ao Judiciário); }\end{array}$ \\
\hline Ros & Tutelar & $\begin{array}{l}\text { - órgão que, ao representar a sociedade, busca substituí-la; } \\
\text { - avoca-se como único capaz de defender a sociedade e agir em prol do bem público; } \\
\text { - o voluntarismo político, a orientação ideológica e a busca pela politização seriam informa- } \\
\text { dos por uma visão de que a sociedade civil é incapaz de defender seus próprios interesses e } \\
\text { de que as instituições políticas cumprem insatisfatoriamente seu papel representativo; } \\
\text { - possui caráter paternalista e verticalizado; }\end{array}$ \\
\hline
\end{tabular}


(conclusão)

\begin{tabular}{|c|c|c|}
\hline Autor & $\begin{array}{l}\text { Modelo de } \\
\text { Atuação }\end{array}$ & Características \\
\hline \multirow[t]{2}{*}{ Ros } & Revolucionário & $\begin{array}{l}\text { - parte do pressuposto que da interação entre Ministério Público e sociedade civil emergem } \\
\text { possibilidades de transformação da realidade social; } \\
\text { - acredita em um potencial virtualmente transformador da realidade social a partir da atuação } \\
\text { da instituição; } \\
\text { - canal de diálogo entre movimentos sociais e Estado; } \\
\text { - palavra-chave = interação; }\end{array}$ \\
\hline & Mediador & $\begin{array}{l}\text { - } \text { órgão de mediação entre vários setores da sociedade civil e do Estado; } \\
\text { - visão mais cautelosa que pretende evitar a construção de imagens totalizantes e lineares; } \\
\text { - não é substituto da sociedade civil e agente de transformações sociais significativas; } \\
\text { - é uma instituição coordenadora das iniciativas sociais; } \\
\text { - de qualquer forma, a atuação permanece dependente de conjunturas específicas, nas quais o } \\
\text { órgão apresentará ora um papel mais tutelar, ora um papel mais transformador. }\end{array}$ \\
\hline
\end{tabular}

\section{Fonte: elaborado pelos autores}

A partir do quadro, verifica-se que, apesar das diferentes maneiras de abordagem e de nominação das práticas, os autores estão de modo geral encontrando basicamente duas formas bastante distintas de atuação do Ministério Público e de seus membros. Nesse sentido, os conceitos e tipos ideais apresentados possuem como núcleo a colocação em lados opostos práticas visivelmente antagônicas. De um lado, práticas demandistas, reativas, tutelares e, de outro, resolutistas, proativas, revolucionárias. As primeiras ligadas à reprodução de uma postura conservadora, verticalizada e passiva diante das desigualdades e dos conflitos sociais contemporâneos e as segundas, afetas a uma nova postura que teria respaldo nos princípios e objetivos fundamentais da Constituição Dirigente de 1988. Essas com profundo potencial transformador (emancipatório) e aquelas marcadamente apegadas ao processo judicial, como único espaço para a concretização de direitos sociais e a pacificação dos conflitos. No caso da judicialização, o braço forte do Estado aparece, seja como autor da ação judicial ou como julgador da contenda, impedindo outras formas de enfrentamento dos conflitos e de obtenção do consenso. Aliás, nada disso é novidade, uma vez que o próprio processo de independência do País decidido entre a elite nacional, a coroa portuguesa e a Inglaterra facilitou - exatamente pela falta de conflito - a continuidade social e a reprodução das desigualdades no Brasil (CARVALHO, 2013). Assim, como afirmado anteriormente, embora partindo de pesquisas e enfoques diversos, os estudos dos autores estão encontrando e apontando basicamente para dois tipos distintos de práticas. 
Ros (2009) apresenta uma classificação tripla, o que destoou dos demais autores. Na revisão da literatura apresentada, o autor lança mão de um terceiro conceito, qual seja, o "MP mediador" para apresentar um tipo ideal que fica no meio entre o tutelar e o revolucionário. Apesar de o conceito manter uma linha tênue entre os dois extremos e destacar a necessidade de cuidados metodológicos, a intenção é mostrar que existe uma posição intermediária que não é nem tutelar e nem revolucionária, mas que deve ser considerada para fins de estudos. Feitas essas considerações, pensamos que o próximo passo seja tensionar a teoria sistematizada neste ponto pelo quadro com as práticas coletadas no campo, para então traçar outros paralelos e desvelar qual o modelo de fato é adotado na Promotoria de Justiça pesquisada. Ou entre os dois modelos bate o coração do Ministério Público?

\section{A LUTA POR UM HOME CARE DENTRO E FORA DO PROCESSO JUDICIAL}

O caso escolhido e etnografado envolveu a vida de uma menina em estado vegetativo, a omissão do poder público e o desespero da família em busca de direitos. Durante longo período, o caso movimentou os esforços de várias pessoas dentro de uma Promotoria de Justiça da Infância e Juventude da Região Metropolitana de Porto Alegre. A aproximação etnográfica ocorreu, por meio de observação participante, entrevista não-diretiva, conversas informais e análise de documentos, desde os atendimentos à família até os desdobramentos recursais no Tribunal de Justiça.

A luta pelo home care iniciou quando a família, sem condições financeiras de arcar com os altos custos do tratamento, recebeu laudo médico prescrevendo o atendimento domiciliar como condição de a menina receber alta hospitalar e evitar novas infecções. Sem os modernos equipamentos e a equipe especializada, indispensável para manter seu corpo vivo, a pequena paciente continuaria indefinidamente ocupando um leito na UTI Pediátrica de um hospital público localizado na Capital do Estado do Rio Grande do Sul. Antes disso, a menina já possuía em seu favor outras ações que buscavam regularizar o fornecimento de vários medicamentos e outros produtos que estavam sempre em falta nas farmácias públicas, tanto municipal quanto estadual. Mesmo com ordens judiciais favoráveis, tanto Município quanto Estado descumpriam sistematicamente as determinações para, por exemplo, o fornecimento de determinados fármacos ou a obrigação de avaliação médica no domicílio, o que, segundo o genitor, levou a essa última internação que resultou no agravamento das sequelas e na necessidade do atendimento home care.

O Ministério Público ajuizou ação civil pública com pedido de antecipação de tutela postulando o serviço

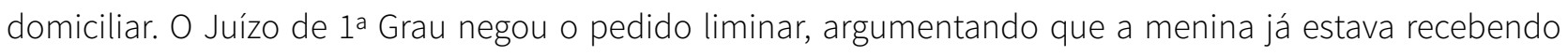
atendimento no hospital e que o serviço tinha alto custo. O Parquet recorreu da decisão e conseguiu reverter 


\section{Gestãoe Desenvolvimento}

o indeferimento junto ao Tribunal de Justiça. A ementa do acórdão sintetiza as razões de decidir do Colegiado (Agravo de Instrumento n. ${ }^{0} x x x x x x x x x x x^{5}$ ):

A manutenção da menor em hospital gera ônus não só ao ente público, mas também à sociedade, na medida em que gera custos para os requeridos e, além disso, mantém um leito ocupado desnecessariamente, retirando a chance de internação de quem realmente necessita da estrutura hospitalar. Opção pelo tratamento domiciliar que se mostra mais adequado ao caso, tanto em relação aos custos para os entes públicos, bem como quanto à qualidade de vida e bem estar da criança enferma.

Todavia, mesmo com a ordem judicial, o poder público executivo, gestor do SUS, não cumpriu a determinação do fornecimento dos serviços em regime domiciliar. A decisão somente foi materializada após bloqueio judicial de valores das contas bancárias dos réus. Entre a alta hospitalar e a efetiva remoção da criança, foram quase 9 (nove) meses de dramas, peregrinações e desconfianças dos familiares em busca da efetivação dos direitos garantidos nas leis e - inclusive - confirmados pelo Poder Judiciário. Lentamente tudo passou pela judicialização, seja pelos reiterados bloqueios de valores para pagamento da empresa prestadora dos serviços, seja pela mediação do Ministério Público em contatos com os entes públicos responsáveis pela gestão do SUS. O Ministério Público tornou-se o balcão da Secretaria de Saúde e das Farmácias Públicas com laudos, receitas, orçamentos e notas fiscais. O pai estava cansado das peregrinações em postos de saúde, hospitais, prefeitura, secretarias de saúde e assistência, farmácias, etc. Indignava-se com as burocracias e a falta de diálogo dos atendentes pelos serviços que percorria em busca de qualidade de vida para sua filha. Em sua entrevista, afirmou: "aqui pelo menos vocês me ouviam, davam tempo para eu falar".

No caso, o Ministério Público teve papel fundamental. Suas práticas garantiram uma sobrevida digna aquela criança junto a sua família e longe das constantes infecções hospitalares. Enfim, o Ministério Público cumpriu com sua missão constitucional de ser defensor dos direitos individuais indisponíveis, conforme dispõe o artigo 127 da CF. Aproximou o Brasil formal e o Brasil real ao insurgir-se contra a violação de direitos de uma criança acometida por um grave acidente doméstico. Aliás, as crianças e os adolescentes possuem pela norma constitucional e legislação infraconstitucional prioridade absoluta. Nesse particular, podemos sugerir que o MP foi transformador da realidade social.

\footnotetext{
${ }^{5}$ Os autores optaram por preservar o anonimato das partes e, assim, por não divulgar o número do processo judicial.
} 
A judicialização, por outro lado, levou ao protagonismo do Estado. Isso porque as ordens judiciais acabam, de uma forma ou outra, por substituir o cidadão na arena política. Com o tempo, a família deixou de cobrar ações do poder público executivo, gestores do SUS, e passou a reclamar tudo diretamente na Promotoria de Justiça. A cada obstáculo, um novo atendimento no Ministério Público. Mas como evitar tal processo neste contexto de doença, pobreza e abandono? Como fazer aquele pai ressignificar a busca de direitos como uma conquista e não como uma dádiva? Aqui - apesar das ponderações - ocorreu a chamada "atuação tutelar do MP" e a "infantilização do cidadão".

O Ministério Público atendeu a demanda social por efetivação de direitos e pela redefinição do papel do direito na sociedade. De espaço conservador, habitado por agentes conservadores encarregados de bloquear demandas políticas das classes baixas, o direito passa a ser utilizado como um instrumento de luta social e espaço mobilizado por diversos grupos sociais para a efetivação de direitos (ENGELMANN, 2013, p. 141). Ao percorrer um caminho cheio de obstáculos e tensões na relação com o Poder Executivo (gestor do SUS) e com o Poder Judiciário, o Parquet deixou - por um lado - evidente o seu protagonismo e ativismo político para a construção de uma sociedade mais livre, justa, igualitária.

De outro, a judicialização dos problemas sociais desloca a discussão do campo político para o mundo jurídico, o que, de certo modo, fragiliza os espaços de discussão, mediação e amadurecimento da sociedade. Se a judicialização se tornar o único caminho, o sistema político democrático sai perdendo com a transferência direta das questões sociais para as mãos do Poder Judiciário. Isso porque ninguém, nem mesmo o Parquet, pode substituir o povo na arena política e na tarefa de indicar quais políticas públicas melhor materializam os direitos previstos na Constituição. O que não se quer é, por um lado, uma instituição paternalista e, por outro, uma sociedade descompromissada com seus problemas, que transfere suas decisões políticas a um ou outro órgão de Estado. Equilibrar essa delicada equação parece ser, neste momento de consolidação e amadurecimento das instituições democráticas, tarefa fundamental para quem pretende ser protagonista na transformação da realidade social e na defesa dos direitos do cidadão.

De qualquer sorte, o Estado (via judicialização) passou a ser o ator central da trama, o que fragiliza a cidadania e a própria democracia. A rede de saúde continuou igual. Mesmo após a ação judicial, os bloqueios de valores e a morte da menina, nada mudou ou muito pouco mudou na realidade dos atendimentos na rede pública de saúde no Município "X”. Novos casos de atendimento home care foram chegando e a solução foi a judicialização. Não parece ter havido qualquer movimento para enfrentar a estrutura que agravou seu estado de saúde e que lhe fez necessitar recorrer a judicialização para receber o atendimento domiciliar. Nos muitos meses em que a menina sobreviveu à custa de bloqueios de valores mensais para pagamentos dos serviços 
e equipamentos de home care, não houve um diálogo com o poder público municipal para qualificação do sistema de saúde e tampouco houve o envolvimento da família nesse sentido. O pai nunca participou das reuniões do Conselho Municipal ou Estadual de Saúde. Uma cidadania ideal pressupõe a participação ativa dos sujeitos na vida política, seja da sua cidade ou do seu país. O cidadão deve ser sujeito de direitos, ou seja, ser o próprio fomentador da existência e efetividade dos direitos (CERQUIER-MANZINI , 2010, p. 12-13). Já o Ministério Público, embora tenha tido sucesso na ação, não sentou com os gestores da saúde para dialogar sobre o caso.

Nesse ponto, vale dizer que o achado é a necessidade de reconhecer essa ambiguidade e qualificar a forma de atuação no sentido de minimizar os efeitos da inevitabilidade do ajuizamento de ações individuais e, consequentemente, do protagonismo do Estado. Ocorre que somente uma instituição capaz de refletir sobre suas próprias práticas e dialogar intensamente com a sociedade é merecedora de ser reconhecida como verdadeiramente transformadora da realidade social e defensora dos direitos do cidadão.

O MP possui o chamado "poder de agenda”. Tal expressão tem sido trabalhada por Sadek (1997, 2009a, 2009b) a partir da liberdade do Ministério Público de escolher qual será a sua pauta de atuação, diferentemente do Poder Judiciário que precisa ser provocado. Todavia, o fato de existir o poder de agenda não significa que o Ministério Púbico esteja concretizando os direitos sociais ou atendendo as demandas sociais. Na verdade, o poder de agenda abre uma "virtualidade" (SADEK, 2009a, p. 133), que poderá ou não ser materializada pela atuação dos seus membros. Na verdade, as práticas indicarão a forma como serão efetivadas essas virtualidades. Daí porque tão importante a sistematização dos modelos de atuação, como os apresentados no quadro do item "3". Aliás, como poderíamos problematizar as ambivalências e as contradições de uma instituição, sem uma base sólida sobre suas práticas e interações no dia a dia?

Nesse contexto, podemos afirmar que práticas demandistas não podem coexistir com práticas resolutistas, sob pena de crise institucional e perda da legitimidade social. Esse é o ponto: "em que medida o discurso adotado - de viés resolutivo - corresponde às práticas diárias das promotorias de justiça" (MACHADO, 2014, p. 135)? Uma atitude verdadeiramente transformadora exige um "promotor de fato" com uma postura "resolutiva", "proativa" e "mediadora". Uma reordenação institucional no sentido de privilegiar o diálogo e a atuação extrajudicial parece ser um caminho em busca da democratização, desburocratização e amadurecimento das relações com a sociedade (e múltiplos atores políticos). Isso porque a simples judicialização, além das implicações em termos de déficits de participação política e cidadania, "traz consigo os males da conhecida letargia dos órgãos jurisdicionais, vítimas de uma indescritível sobrecarga de trabalho, e de um anacrônico sistema processual" (GARCIA, 2008, p. 386). 
Antes de passar às considerações finais, queremos apenas pontuar, que a questão da cidadania é bastante complexa. Ela não se resume a conceitos clássicos e nem a tipos ideais da ciência política a apontar aqui ou acolá um déficit de cidadania. No caso, poderíamos destacar as peregrinações do genitor pelos órgãos públicos e a sua constante presença na Promotoria como uma resistência aos obstáculos impostos pelas próprias leis e pelas burocracias ao acesso aos direitos. Se destacarmos a agência das pessoas, encontraremos certamente luta, astúcia e persistência. De que adiantaria bater em portas que nunca lhe são abertas ou falar para quem nunca lhe dá ouvidos? Esta reflexão é para deixar registrado que não podemos simplificar as dores daquela família, em especial daquele pai. Como falar em cidadania, se sequer o direito à vida, sem o qual nenhum outro existe, possui uma proteção efetiva do Estado? Da mesma forma, não há como desconsiderar que a judicialização, em que pese eventuais ponderações críticas, tem sido um espaço para concretização de direitos sociais e luta de grupos por demandas como saúde, educação e assistência. Todavia, a análise pormenorizada nessa perspectiva, na qual a antropologia e seu característico método de pesquisa pode muito contribuir, merece um espaço maior em um futuro estudo mais sensível às dores humanas silenciadas em papéis dentro de processos judiciais.

\section{CONCLUSÃO}

O presente artigo é parte de um esforço interdisciplinar na tentativa de superar legalismos, formalismos e estereótipos típicos do discurso jurídico quando descontextualizado das práticas sociais e do cotidiano vivido por pessoas em busca de direitos nas instituições que compõem o Sistema de Justiça. O diálogo entre o direito e a antropologia pode produzir um conhecimento que escapa às generalizações, homogeneidades e simplificações. Note-se que a letra da lei não tem sido suficiente "para explicar essa instituição que, na sua origem, defendeu os interesses da Coroa e da Administração, e, contemporaneamente, cumpre a função de defender os valores democráticos e os interesses do povo" (GOULART, 2013, p. 82). Não por outra razão, as ciências humanas e sociais começam a olhar - e aqui reside o especial interesse deste estudo - com maior atenção e profundidade para o Ministério Público. Aliás, ao cientista social cabe a tarefa de reconhecer as dialéticas da vida social (DAMATTA, 1997) e questionar os mitos que a sociedade usa para sobreviver (SOUZA, 2012).

No pequeno recorte teórico, a revisão da literatura apontou que existem estudos indicando basicamente dois tipos de práticas bastante distintas dos membros do Ministério Público. Traçando um paralelo entre os pontos de encontro e de contraste é possível inclusive criar, para fins didáticos, um novo quadro com a essência dos referidos modelos. De um lado do quadro, recuperamos um padrão (tradicional, burocrático e judicial) de atuação encontrado pré-1988; de outro lado, um padrão (moderno, desburocratizado e 
extrajudicial) que teoricamente deveria ser encontrado pós-1988. Este último possui uma atuação próxima daquilo que caracterizaria uma prática em consonância com a nova ordem jurídica e sua defesa da democracia participativa, da dignidade da pessoa humana, da cidadania e do pluralismo político, da erradicação da pobreza e da marginalização, da promoção do bem de todos, etc. Vejamos o quadro:

Quadro 2 - Modelos

\begin{tabular}{|c|c|}
\hline Modelo 1 & Modelo 2 \\
\hline $\begin{array}{l}\text { Atuação voltada à solução das demandas, preferencialmente } \\
\text { pela via de processos perante o Poder Judiciário }\end{array}$ & $\begin{array}{l}\text { Atuação voltada à solução das demandas, preferencialmente } \\
\text { pela via extrajudicial }\end{array}$ \\
\hline Transfere ao Juiz a decisão sobre o conflito & As partes envolvidas negociam uma solução para o conflito \\
\hline $\begin{array}{l}\text { Os instrumentos extrajudiciais, como o IC e o TAC, são } \\
\text { utilizados prioritariamente como meio de coleta/produção de } \\
\text { provas para instruir futura ação judicial }\end{array}$ & $\begin{array}{l}\text { Os instrumentos extrajudiciais, como o IC e o TAC, são } \\
\text { utilizados prioritariamente como meio de diálogo, } \\
\text { participação e negociação do Ministério Público com a } \\
\text { sociedade social e o Poder Público }\end{array}$ \\
\hline Passivo (recebe as demandas) & Ativo (elege as demandas) \\
\hline Atuação repressiva & Atuação preventiva \\
\hline $\begin{array}{l}\text { Distante da política local (até ser provocado ou, até mesmo, } \\
\text { após ser provocado) }\end{array}$ & Fomentador e articulador da política local \\
\hline $\begin{array}{l}\text { Representa práticas conservadoras em descompasso com a } \\
\text { nova ordem constitucional }\end{array}$ & $\begin{array}{l}\text { Representa práticas transformadoras em sintonia com a nova } \\
\text { ordem constitucional }\end{array}$ \\
\hline Poder de agenda limitado & Poder de agenda ampliado \\
\hline
\end{tabular}

\section{Fonte: elaborado pelos autores}

Após a construção desse novo quadro que sintetiza ainda mais os resultados encontrados na revisão da literatura, a pergunta que emerge é no sentido de qual padrão é o dominante? A resposta contextualizada - obtida pelas evidências etnográficas colhidas no trabalho de campo - é de que as práticas transitam de um extremo ao outro. É pseudocientífico falar de padrões sem uma séria contextualização. A aproximação 
etnográfica demonstra que as práticas são complexas, relacionais e, às vezes, contraditórias, sendo que, na maioria das vezes, passam despercebidas quando focamos nossa análise e compreensão apenas em estatísticas descontextualizadas ou em dados obtidos somente dentro dos processos judiciais. Nesse aspecto, a contribuição do pesquisador social deve ser no sentido de problematizar determinadas práticas naturalizadas, ou seja, questionar mitos que cercam as práticas institucionais e sociais.

A pesquisa também abriu uma reflexão importante sobre a sistemática e contumaz judicialização dos problemas sociais. Nesse particular, foi possível perceber que a Instituição, ao mesmo tempo em que judicializa os problemas sociais e, por meio de ações judiciais, concretiza os direitos sociais (dado positivo), também centraliza o debate sobre direitos e reforça a centralidade do Estado (dado negativo), reproduzindo velhas estruturas de poder e dominação facilmente identificadas na história brasileira. Em alguns casos, a atuação excessivamente tutelar infantiliza as pessoas atendidas e cria certa dependência do órgão estatal Ministério Público. Aqui a Instituição reproduz um modelo de atuação que deveria estar ultrapassado diante dos paradigmas da Constituição Federal de 1988. Todas essas nuances só demonstram a complexidade das relações possíveis entre a atuação do Ministério Público e seus desdobramentos em termos de cidadania.

Independente das adjetivações da literatura, seja na luta pela concretização dos chamados novos direitos, seja na tradicional tarefa de combate ao crime, o Promotor de Justiça deve estar acessível ao povo, que é o destinatário primeiro e último do seu trabalho. Ele deve abandonar o silêncio do gabinete e promover audiências públicas para ouvir as comunidades esquecidas pelo poder público e, muitas vezes, pelo próprio Direito. Deve dar voz a quem nunca teve direito a ter direitos. O Ministério Público não pode ser nada menos de que o verdadeiro defensor do regime democrático, da ordem jurídica e da própria sociedade. Dele se espera a transformação da realidade social e a proteção dos direitos fundamentais, por meio da indução e da fiscalização das políticas públicas. Deve ser um MP que, para além da semântica da letra da lei, sintonize na mesma direção sua relevante missão constitucional e suas práticas institucionais. Uma maior interação com a sociedade pode ser uma forma de intensificar a fiscalização de políticas públicas para a infância e de identificar casos semelhantes ao etnografado. Uma reordenação institucional para priorizar ações preventivas e projetos extrajudiciais poderia suprir lacunas também encontradas por outros pesquisadores. Nesse sentido, vale citar as palavras de Nunes Júnior (2004, p. 28-29):

De igual forma, o Ministério Público poderia colocar-se como uma espécie de incentivador das organizações não-governamentais, concorrendo para a criação e incentivando e apoiando a atuação de associações civis, como, por exemplo, as dedicadas à defesa do consumidor e dos direitos humanos. Todo esse processo, evidentemente, não surgirá de decisões burocráticas ou de processos judiciais a 
serem instaurados. O que deve acontecer é uma interação, ou, em outras palavras, uma efetiva inserção do Ministério Público e de seus agentes no meio social. (...) Como se falar em proteção da infância sem uma relação estreita com os Conselhos Tutelares e, porvia de consequência, sem conhecimento dos problemas que afligem a infância e a juventude nas diversas regiões da cidade? Na verdade, o que parece é que o ponto básico de uma reordenação institucional seria exatamente uma inserção mais significativa do Ministério Público no meio social.

O Ministério Público é, de fato, uma Instituição grande, complexa e multifacetada. Com efeito, reconhecer que suas práticas transitam de forma simultânea entre um modelo e outro pode ser um começo para formularmos uma resposta fundamentada à questão da emancipação. Uma postura demandista, de gabinete e reativa não conduz à emancipação e sim, à dependência, pois somente reproduz estruturas tutelares e burocráticas dentro do Sistema de Justiça Brasileiro.

De outro lado, avançando nessa linha de raciocínio, outras perguntas já poderiam ser formuladas: A instituição que na sua atuação diária revela igualmente práticas transformadoras da realidade social e reprodutoras das desigualdades sociais cumpre a sua missão? Ela pode, entre avanços e retrocessos, entre modelos tão distintos de trabalhar e de interagir com a sociedade, ser espaço de promoção do exercício da cidadania? Qual Ministério Público queremos para atender os anseios de uma sociedade cuja herança maior é a extrema desigualdade social e suas consequências (pobreza, violência, etc.)? Será a Instituição que burocratiza seus procedimentos e descuida da sua atividade-fim? Será o Promotor que simplesmente contabiliza ações na comarca ou que utiliza instrumentos extrajudiciais (ex: Inquérito Civil, Termo de Ajustamento de Conduta, Audiência Pública) para mediar a solução dos conflitos? Que ignora ou dialoga com os grupos sociais? Que blinda o seu gabinete à vida real? As correspondentes respostas passam por novas pesquisas interdisciplinares e são fundamentais para pensar o futuro da Instituição e do próprio Estado Democrático de Direito. E pensar é sempre um bom começo! 


\section{REFERÊNCIAS}

ARANTES, Rogério Bastos. Direito e Política: o Ministério Público e a defesa dos direitos coletivos. Revista Brasileira de Ciências Sociais, São Paulo, v. 14, n. 39, p. 83-102, fev. 1999.

Ministério Público na fronteira entre justiça e a política. Justitia, São Paulo, v. 64, n. 197, p. 325-338, jul./dez. 2007.

CARVALHO, José Murilo. Cidadania no Brasil: o longo caminho. 17. ed. Rio de Janeiro: Civilização Brasileira, 2013.

CERQUIER-MANZINI, Maria Lourdes. O que é Cidadania. 4. ed. São Paulo: Brasiliense, 2010.

DAMATTA, Roberto. Carnavais, Malandros e Heróis: para uma sociologia do dilema brasileiro. 6.ed. Rio de Janeiro: Rocco, 1997.

ENGELMANN, Fabiano. Cidadania e efetivação de direitos no Brasil: caminhos e perspectivas. In: MACHADO, Carlos R. S.; MARTINS, Rodrigo Perla (Org.). Identidades, Movimentos e Conceitos: fundamentos para a discussão da realidade brasileira. 2. ed. Novo Hamburgo: Feevale, 2013. p. 138-144.

GARCIA, Emerson. Ministério Público: Organização, Atribuições e Regime Jurídico. 3. ed. Rio de Janeiro: Lumen Juris, 2008.

GOULART, Marcelo Pedroso. Elementos para uma teoria geral do Ministério Público. Belo Horizonte: Arraes Editores, 2013.

Ministério Público: estratégia, princípios institucionais e novas formas de organização. In: LIVIANU, Roberto (Org.). Justiça, cidadania e democracia. São Paulo: Imprensa Oficial do Estado de São Paulo: Ministério Público Democrático, 2006.

LOUREIRO, Ythalo Frota. A atuação proativa do Ministério Público na busca da efetividade dos Direitos Fundamentais. Revista Acadêmica da Escola Superior do Ministério Público do Ceará, Fortaleza, v. 2, n. 1, jan./jun. 2010.

MACHADO, Eduardo de Paula. Ministério público, gestão social e os conselhos gestores de políticas públicas. Revista do Conselho Nacional do Ministério Público, Brasília , v. 2, n. 4, p. 111-139, jul. 2014. 
MAGNANI, José Guilherme Canto. De perto e de dentro: notas para uma etnografia urbana. Revista Brasileira de Ciências Sociais, v. 17, n. 49, p. 11-29, 2002.

MAZZILLI, Hugo Nigro. O Ministério Público - lutas e conquistas. Revista da Associação Paulista do Ministério Público, São Paulo, v. 13, n. 48, p. 4-7, set./dez. 2008b.

NUNES JÚNIOR, Vidal Serrano. Ministério Público e Defesa da Cidadania. In: PINSKY, Jaime (Org.). Práticas de Cidadania. São Paulo: Contexto, 2004. p. 21-29.

ROS, Luciano da. Ministério Público e Sociedade Civil no Brasil Contemporâneo: em busca de um padrão de interação. Revista Política Hoje, v. 18, n. 1, p. 29-53, 2009.

SADEK, Maria Tereza. A construção de um novo ministério público resolutivo. De Jure - Revista Jurídica do Ministério Público do Estado de Minas Gerais, Belo Horizonte, n. 12, p. 130-139, jan./jun. 2009a.

O Ministério Público e a Justiça no Brasil. São Paulo: IDESP/Sumaré, 1997.

Ministério público: um olhar externo. Revista Jurídica do Ministério Público de Mato Grosso, Cuiabá , v. 4, p. 27-39, jan. 2009b.

SANTOS, Boaventura de Sousa. Poderá o Direito ser emancipatório? Revista Crítica de Ciências Sociais, Coimbra, n. 65, p. 3-76, mai. 2003.

SILVA, Cátia Aida. Justiça em Jogo: Novas Facetas da Atuação dos Promotores de Justiça. São Paulo: Edusp, 2001a.

. Promotores de Justiça e Novas Formas de Atuação em Defesa de Interesses Sociais e Coletivos.

Revista Brasileira de Ciências Sociais, São Paulo, v. 16, n. 45, p. 127-144, fev. 2001 b.

SOUZA, Jessé. A Construção Social da Subcidadania. 2. ed. Belo Horizonte: UFMG, 2012.

VELHO, G. Observando o familiar. In: NUNES, E. de O. (Org.). A aventura sociológica: objetividade, paixão, improviso e método na pesquisa social. Rio de Janeiro: Zahar, 1978. p. 36-47. 